\title{
Ranging of older male elephants introduced to an existing small popula- tion without older males: Pilanesberg National Park
}

\author{
R. SLOTOW and G. VAN DyK
}

Slotow, R. and G. van Dyk. 2004. Ranging of older male elephants introduced to an existing small population without older males: Pilanesberg National Park. Koedoe 47(2): 91-104. Pretoria. ISSN 0075-6458.

African elephant have been introduced to small reserves in southern Africa as rangelands are converted to game reserves. Early introductions were limited to very young individuals ( $<10$ years old), and these populations have manifested abnormal behaviour. This project aimed to rectify this by creating a more normal population age structure. Six older (25 to 35 year old) male elephant were introduced from Kruger National Park to Pilanesberg National Park from February 1998. These radio-collared individuals were followed intensively. Immediately after release, the males demonstrated exploratory behaviour before settling down in very small home ranges. Core home range size (50 \% Kernel) was 3-23 km², while total home range (95\% Kernel) was 24-139 km² (total reserve size $=500 \mathrm{~km}^{2}$ ). There was no indication of homing towards the direction of their origin. During musth, males shifted their spatial use to coincide with that of females, and walked significantly longer distances while in musth. These results imply that males were moving from 'bull areas' to join the female groups when they came into musth. The limited range used by males for most of the year has very important implications for managers of small reserves. Firstly, large adult males can be maintained on very small reserves, and secondly, the impact of large males on their environment will be extremely heterogeneous, with some areas severely impacted, and others with little or no impact. This study highlights the importance of detailed individual behavioural knowledge of large mammals in understanding their potential ecological contribution to the ecosystem. The consequences of heterogeneous spatial use need to be well modelled for any meaningful management plan of elephant to be generated.

Key words: Loxodonta africana, reintroduction, homing, home range, movement

R. Slotow $\varangle$, School of Life \& Environmental Sciences, University of KwaZulu-Natal, Durban, 4041 Republic of South Africa, (slotow@ukzn.ac.za); G. van Dyk, School of Life \& Environmental Sciences, University of KwaZulu-Natal, Durban, 4041 Republic of South Africa (present address: Pilanesberg National Park, North West Parks and Tourism Board, P.O. Box 1201, Mogwase, 0314 Republic of South Africa).

\section{Introduction}

The African elephant Loxodonta africana is one of the key components of African savanna. Not only do they play a crucial role in the ecosystem (Dublin et al. 1990; Van de Vijver et al. 1999), but they also provide one of the integral parts of sustainable conservation through ecotourism (e.g. Brown 1993) and consumptive utilisation (Taylor 1993).

The ever-expanding transformation of savanna land-use through human settlement is resulting in the isolation of elephants into small populations. Furthermore, in South Africa, the reclamation of ranch land as game areas has resulted in the reintroduction of elephant to a large number of small, isolated, fenced reserves.

Elephants potentially modify their environment, and managers of small reserves are faced with the 'elephant problem' (Caughley 1976), the loss of aesthetically important large trees and potential adverse effects on biodiversity. This is particularly pertinent for older male elephant that regularly push over the larger trees in their range (pers. obs.). 
However, elephants do not utilise all of their range equally, and such adverse effects are likely to be heterogeneous. To more effectively model the potential effects of elephant, and thus provide managers with more comprehensive data for which to set stocking rates of small reserves, detailed knowledge of spatial behaviour of elephant is required. An aim of this paper is to describe spatial use by older male elephants in a small reserve, and further to describe variation in use in relation to behaviour such as musth (see Poole 1987 for definition), and which will provide a useful contrast with a recent study at Addo Elephant National Park (Whitehouse \& Schoeman 2003).

Before 1998, all small elephant populations in South Africa that were founded through reintroduction lacked older males (> 25 yrs). This was because of technological constraints on moving large animals, and trucks large enough to move males were developed for this introduction project. Subsequent to the success of this project a large number of reserves have introduced larger males with mixed success (Garai \& Carr 2001), and it is likely that most of the small populations in southern Africa will receive older males in the coming years. The second aim of this paper is to provide a description of the spatial use of elephants that are introduced to an existing population.

The main reason for the introduction of these older males was that the younger males were displaying abnormal behaviour in that they were killing white rhino Ceratotherium simum while in musth (Slotow et al. 2001; Slotow \& van Dyk 2001). The young males were entering musth at an early age, and the older males were introduced from Kruger National Park in order to suppress musth in these young bulls. This proved successful, and the musth patterns of the young males before and after introduction, and of the older bulls is described elsewhere (Slotow et al. 2000).

\section{Methods}

Pilanesberg National Park $\left(25^{\circ} 8^{\prime}-25^{\circ} 22^{\prime}\right.$ S; $26^{\circ} 5^{\prime}-$ $27^{\circ} 13^{\prime} \mathrm{E}$ ) is situated in the remains of an extinct volcano. It comprises $500 \mathrm{~km}^{2}$ of very hilly savanna terrain. The habitat consists of Acacia and broad-leaf bushveld which ranges from thickets to open grassland patches. There is one major river system running southeast through the central part of the park, and a large dam in the centre of the park, with a number of smaller dams scattered throughout the reserve. Rainfall is approximately $630 \mathrm{~mm}$ p.a., and falls in summer. Winters are cold (minimum temperature $1-5^{\circ} \mathrm{C}$ ), and summers very hot (mean temperature $28-31^{\circ} \mathrm{C}$ ). The park was proclaimed in 1979 , and since then, about 6000 individuals from a range of species have been reintroduced to the park.

African elephants were introduced from Kruger National Park in 1981 (13 juvenile males; 5 juvenile females), 1983 (13 juvenile males; 11 juvenile females), 1993 (19 males; 17 females) and, from Namibia in 1982 (1 juvenile male; 1 juvenile female). At the time of the introduction, the technology of translocations was such that elephants of a maximum shoulder height of $2 \mathrm{~m}$ (8-10 years old) could be translocated live. The elephants that were translocated were orphans from culling operations. In 1982, two 19-year-old females were introduced. These were tame elephants that were returned from the USA to Africa, and released into the wild. These two older females assumed the role of matriarchs in the Pilanesberg herds. Two young male elephants were introduced from Mabula Lodge in 1992 and were removed in March 1993. The first young elephant was born in 1989, indicating that males were breeding at the age of about 18 years old. There were a total of 93 elephant in the population at the start of this study in early 1998, with 17 individually recognizable independent males. These were males that had left the female groups, and were consistently alone or with other males. They ranged in age from 18 to 25 years old.

Six older male elephants were introduced from Kruger National Park in early 1998 (Table 1). These were captured separately and moved in pairs. Each pair was immobilised in the morning from a helicopter, and transported in a specially built trailer to be released into a holding facility in Pilanesberg on the evening of the same day. Each pair was held for one to three nights and then released by opening the gate in the morning, and the animals moved out of the facility that night. The elephants had vocal contact with the existing population, but no physical contact because the fence of the facility was electri- 
fied inside and out. The park border fence is also electrified and provides a barrier to elephants.

All independent male and adult female elephants in Pilanesberg are identified through unique ear, trunk, tail and tusk characteristics. All six introduced males were fitted with VHF radio-collars. A dedicated assistant monitored the elephants from introduction until the end of May 1999. From November 1998, a second assistant was working on the rhino population, and included additional sighting information. From June 1999, the latter assistant monitored the elephants, but at a lesser intensity than previously. In July 1998, December 1998 and July 1999 volunteer undergraduates from the University of Natal provided additional sightings. Several tourist guides driving open viewers in the park and park staff also provided additional information.

At each sighting elephants were identified using a master file, and the following information was recorded: date, time, grid location $(500 \mathrm{~m} \times 500 \mathrm{~m}$ grid), GPS location (without correction), IDs, total group size, number males, number females, number young, habitat type (one of 22 types). In addition, time budgets were recorded where possible. Pilanesberg consists of bushveld, making it difficult to observe animals, and most observations were made from a vehicle from the road. There is an extensive road network in Pilanesberg (Fig.1). However, there are two large wilderness areas that are traversed by few tracks, and some areas are completely inaccessible. The larger one is in the northwest and the other in the south-east of the reserve. Elephants did 'disappear' into these 'black holes' for varying periods.

Until May 1999, the assistant attempted to get a daily location on each of the six introduced bulls using telemetry. From June 1999, sightings became more opportunistic, and the frequency of sighting each individual decreased. During the first year, the assistant would walk in on collared animals in order to get group information, but this effort was reduced as the study proceeded.

\section{Data Analysis}

Data were processed in Excel (Microsoft), and imported to Arcview (ESRI). Maps were produced covering six-month periods, and each record was checked on a master spreadsheet against the maps for accuracy. Suspected errors and duplicate records were deleted. Observations of the same animal on the same day were retained if the records were early morning (before 10:00) or late afternoon (after 16:00) or if there had been a substantial change in location (at least $1 \mathrm{~km}$ ).
Data were captured in Latitude and Longitude, and projected into UTM using WGS84 projection. The master file is lodged at the University of KwaZuluNatal and with the Database Manager, Ecological services, North West Parks \& Tourism Board. The master file was processed into separate files that contained selected periods. These periods were selected separately for each individual, and reflected changes in spatial use (settled in one area or moving widely across reserve), or behaviour (in or out of musth, with or without female groups). An individual was considered as settled when the locations could be contained within a single kernel during a kernel analysis, and as moving when the locations ranged outside of the kernel, and were not repeatedly in the same place. Although this was a subjective assessment, whether an individual should be included in a specific category was unambiguous in each case. Each of these files was then processed in two ways using the Arcview extension called Spatial Movement Analysis (Hooge \& Eichenlaub 1997). Firstly, if the elephants were moving widely, a sequential route was produced using the 'create polyline from point file function'. Secondly, Kernel Home Ranges were produced using the 'kernel home range function (with $\mathrm{H}=500 \mathrm{~m}$ )' to indicate ranges. We present $95 \%$ (assumed to indicate greatest range extent) and $50 \%$ (assumed to indicate core range area) probability kernels (Worton 1989).

Overlaps in areas were calculated by overlaying maps of the prior behaviour with the selected behaviour, and then dividing the area of overlap by the prior area (multiplied by 100), to give a percentage overlap area. Male ranges before and during musth were contrasted with ranges for females. During the period of the study there were three groups of females. The matriarch of the one group of about 16 animals was collared, and the other two groups regularly joined to form a single large group. Male \#33 spent most of his time with females in this large group. Females were therefore sighted as often as the males. We generated home ranges for the females for the periods whenever a male was in musth and assessed overlaps in the same way as above.

\section{Results}

Each individual was located on average 336 times during the period of the study (Table 1). Almost two thirds of those sightings were up to the end of 1998 (average 235 sightings over about 330 days) giving an average sighting rate per elephant of greater 
a
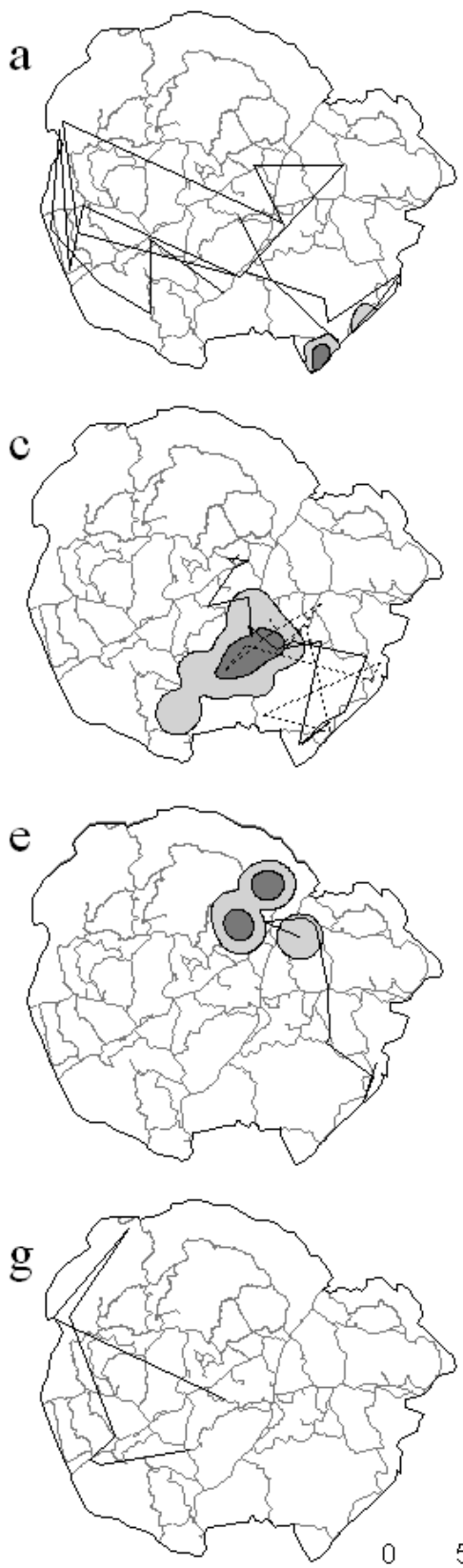

b
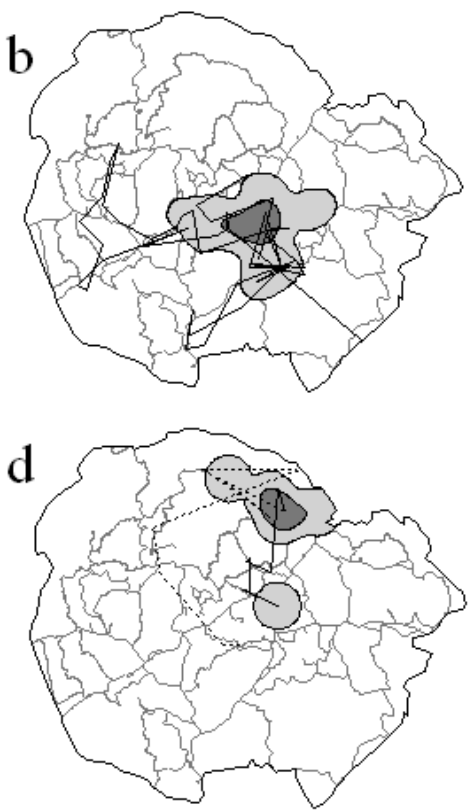

f

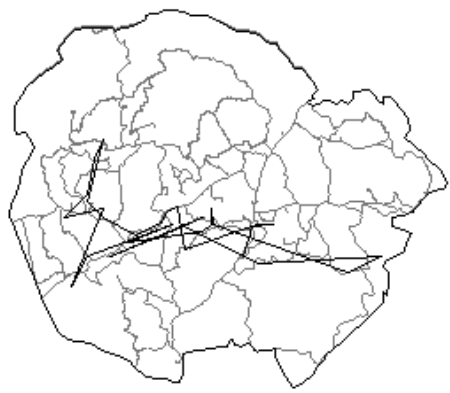

10 Kilometers

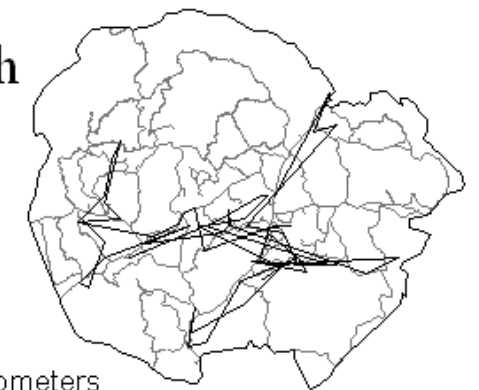

Fig. 1. Ranging patterns of older male elephants on introduction to Pilanesberg National Park. (a) Male \#30: route from introduction until 7 March 1998 and kernel range of first settlement from 8 to 24 March 1998. (b) Male \#30: route from 26 March to 29 April 1998 and kernel range of second settlement period from 30 April to 31 May 1998. (c) Male \#30: kernel range 1 to 30 June 1998, solid line showing route from 1 to 13 July 1998, dashed line showing route from 25 July to 10 August. (d) Male \#31: kernel range from 17 February to 3 March 1998, dashed line showing route from introduction to 17 February 1998, solid line showing route from 3 March to 13 March 1998. (e) Male \#31: kernel range from 14 March to 1 April 1998, line showing route from 2 April to 14 April 1998. (f) Male \#32: initial range from introduction to 15 April 1998. (g) Male \#33: initial range from introduction to 2 April 1998. (h) Males \#34 \& \#35: initial range from introduction until 24 April 1998. See Appendix A for additional information. 
Table 1

Physical characteristics, release dates, and sample sizes of six large male elephants introduced to Pilanesberg National Park from Kruger National Park

\begin{tabular}{lccccccc}
\hline & & & & \multicolumn{2}{c}{ Percent of sightings on: } \\
\cline { 6 - 8 } & $\begin{array}{c}\text { Release } \\
\text { Date } \\
(1998)\end{array}$ & $\begin{array}{c}\text { Est. } \\
\text { Age }\end{array}$ & $\begin{array}{c}\text { Total number } \\
\text { of sightings }\end{array}$ & $\begin{array}{c}\text { Number of } \\
\text { sightings to } \\
\text { end 1998 }\end{array}$ & $\begin{array}{c}\text { Same } \\
\text { day }\end{array}$ & $\begin{array}{c}\text { Subsequent } \\
\text { day }\end{array}$ & $\begin{array}{c}\text { Same or } \\
\text { subsequent } \\
\text { day }\end{array}$ \\
\hline 30 & 7 Feb & 33 & 362 & 274 & 21 & 55 & 76 \\
31 & 7 Feb & 29 & 285 & 205 & 15 & 39 & 54 \\
32 & 22 Mar & 35 & 335 & 242 & 19 & 44 & 63 \\
33 & 22 Mar & 25 & 284 & 192 & 16 & 35 & 51 \\
34 & 13 Mar & 31 & 397 & 264 & 20 & 43 & 63 \\
35 & 13 Mar & 32 & 353 & 233 & 17 & 42 & 59 \\
\hline Mean & & & 336 & 235 & 18 & 43 & 61 \\
\hline
\end{tabular}

than 2 days in every three for the calendar year 1998.

The sightability varied among individuals. We calculated the proportion of all sightings that were made on the same or subsequent day, i.e., within 36 hours of each other as 0.76 for male \#30, but this dropped to 0.51 of 284 sightings for male \#33 (Table 1). There were periods when the elephant were out of sight and others when they were regularly seen. For example, male \#35 was accessible over a longer period than male \#30, but male \#30 was seen more often while he was accessible. Details of movements over selected periods for each male are presented in Appendix A.

\section{Initial period following introduction}

All of the introduced males displayed some form of exploratory movement before settling into restricted areas. There was however variation both in the extent, and the timing of the explorations. Male \#30 showed the widest initial movement (Fig. 1a - line) ranging across $2 / 3$ of the reserve over a period of 28 days. Male \#30 then settled in the southwestern part of the park for the next 16 days (Fig 1a - kernels). Following this there was a further exploration (Fig. 1b - line) and then male \#30 settled in a compact home range in the centre of the reserve (Fig. 1b kernels).

Male \#31 was slightly injured in the left front leg during the translocation process. This may have effected his initial movement. Male \#31 showed a much shorter exploration initially (Fig. 1d -dashed line), and settled in a compact range in thickets in the north (Fig 1d - kernels). A second short exploration (Fig 1d - solid line) was followed by a return to the north where male \#31 settled in a compact home range until 1 April 1998 (Fig. 1e kernels). A longer exploration occurred from 1 April to 14 April 1998 when male \#31 visited the southeast of the reserve (Fig 1e solid line).

Male \#32 showed intermediate exploration, visiting about half of the reserve, before settling in a large range in the centre of the reserve (Fig. 1f). Male \#33 showed the least exploration (Fig. 1g) and then joined up with the largest female group, and ranged with them. Males \#34 and \#35 consistently moved together until 25 April 1998. They showed extensive ranging (Fig. 1h) before settling in the centre of the park (Fig. 2m).

None of the elephants showed a tendency to move to, or to settle in the direction of their origin in the Kruger National Park. The first movement in all cases was in a direction 

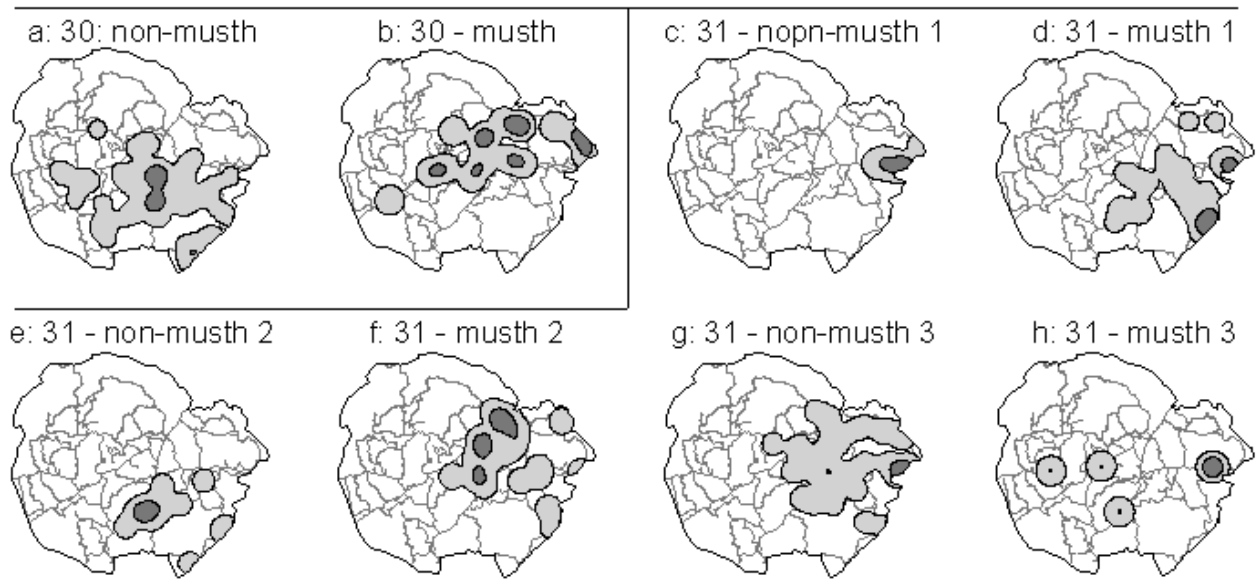

h: 31 - musth 3
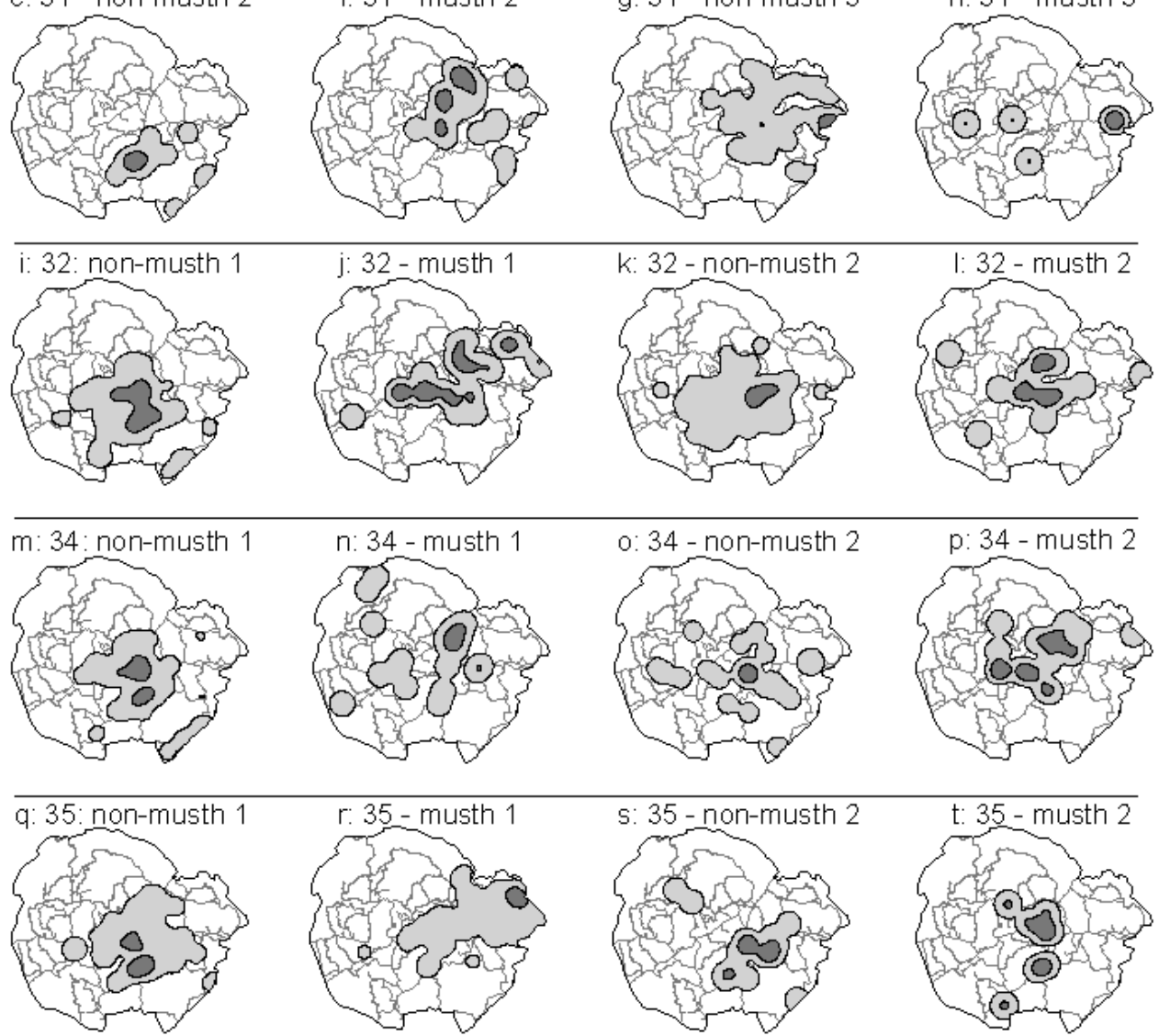

Fig. 2. Contrast of ranging patterns before and during musth for older bulls introduced to Pilanesberg National Park. (a) Male \#30 pre-musth: 4 Jan to 17 Dec 1999. (b) Male \#30 musth: 24 Dec 1999 to 28 Feb 2000. (c) Male \#31 pre-musth 1: 9 Aug to 2 September 1998. (d) Male \#31 musth 1: 11 Sep to 2 Nov 1998. (e) Male \#31 pre-musth 2: 3 to 24 Nov 1998. (f) Male \#31 musth 2: 25 Nov 1998 to 4 Jan 1999. (g) Male \#31 premusth 3: 2 Mar to 6 Oct 1999. (h) Male \#31 musth 3: 18 Oct to 23 Nov 1999. (i) Male \#32 pre-musth 1: 16 Apr to 25 Nov 1998. (j) Male \#32 musth 1: 28 Nov 1998 to 10 Jan 1999. (k) Male \#32 pre-musth 2: 11 Jan to 13 Dec 1999. (l) Male \#32 musth 2: 16 Dec 1999 to 16 Feb 2000. (m) Male \#34 pre-musth 1: 26 Apr to 5 Dec 1998. (n) Male \#34 musth 1: 7 Dec 1998 to 28 Jan 1999. (o) Male \#34 pre-musth 2: 23 Jun to 13 Dec 1999. (p) Male \#34 musth 2: 16 Dec 1999 to 7 Feb 2000. (q) Male \#35 pre-musth 1: 17 Nov 1998 to 1 Apr 1999. (r) Male \#35 musth 1: 10 Apr to 20 Aug 1999. (s) Male \#35 pre-musth 2: 21 Aug to 19 Dec 1999. (t) Male \#35 musth 2: 10 Jan to 7 feb 2000. 
Table 2

Movement of older adult male elephant introduced from Kruger Park to Pilanesberg. Distances are calculated as straight-line distance between points of observation on two sequential days separated by a night period (except first values column)

\begin{tabular}{lccccccc}
\hline \multicolumn{7}{c}{ Average distance (km) moved between sightings } \\
\hline ID & $\begin{array}{c}\text { on the } \\
\text { same day }\end{array}$ & $\begin{array}{c}\text { on } \\
\text { subsequent } \\
\text { days }^{2}\end{array}$ & $\begin{array}{c}\text { during } \\
\text { initial } \\
\text { period }\end{array}$ & $\begin{array}{c}\text { during } \\
\text { non-musth } \\
\text { periods }\end{array}$ & $\begin{array}{c}\text { during } \\
\text { musth } \\
\text { periods }\end{array}$ & $\begin{array}{c}\text { when with } \\
\text { females }\end{array}$ & $\begin{array}{c}\text { when not } \\
\text { with } \\
\text { females }\end{array}$ \\
\hline 30 & 2.0 & 2.9 & 5.4 & 2.3 & 4.1 & & \\
31 & 1.7 & 3.4 & 3.8 & 3.1 & 5.5 & & 4.5 \\
32 & 2.0 & 3.5 & 3.4 & 2.7 & 4.4 & 4.3 & \\
33 & 1.7 & 4.5 & 5.5 & & & & \\
34 & 2.5 & 4.1 & 3.2 & 3.7 & 5.2 & & \\
35 & 2.7 & 4.3 & 3.7 & 3.3 & 7.1 & & \\
\hline mean & 2.1 & 3.8 & 4.2 & 3.0 & 5.3 & & \\
\hline
\end{tabular}

Data are averages of average values for all separate periods for each individual (Appendix A).

${ }^{1}$ Distance between two points on the same day separated by at least $6 \mathrm{~h}$ and $1 \mathrm{~km}$ (see methods).

${ }^{2}$ Distance between two points on subsequent days.

other than the Kruger National Park (situated due East).

We calculated the distance moved from observations made on two sequential days. Five of the six males showed substantially longer movement during the initial period relative to the subsequent period (Table 2). This result was marginally non-significant (Wilcoxon test: $z=-1.787, n=6, p=0.074$ ). This test has extremely low power, and is most probably a biologically significant result. Given that all males showed some initial exploration, we interpret the increased movement as extra distances moved in association with exploration.

For male \#30 there was a substantial difference in the distance moved between observations on subsequent days when contrasting the period when settled ( mean $=2.6 \mathrm{~km}$ ) versus those during when he was moving (3.4 km) (Fig 1a, b, c; Appendix A). These differences in distance moved per day were marginally non-significant (Wilcoxon paired signed ranks test: $z=-1.84, n=4$ paired periods, movement period paired with subsequent settled period; $p=0.066$ ). A similar contrast for male \#31 indicated the same pattern, but with non-significant differences (mean settled $=2.4 \mathrm{~km}$; mean ranging $=$ $3.1 \mathrm{~km}$; Wilcoxon test: $z=-0.7, p=0.47$; Appendix A)

Comparable data for the other individuals were not available because they did not show such clearly dichotomous (settled vs nonsettled) behaviour (see below).

\section{Subsequent ranging behaviour}

All of the males settled into restricted ranges within the reserve. They spent extended periods in a local area, and then went 'walkabout' moving extensively, followed by settlement into another local area. There may have been some shift in the local areas.

After the initial movements and settled periods detailed above, from August 1998 through to the end of 1999 male \#30 remained in a restricted range in the centre of the reserve (Fig. 2a). The major change in ranging patterns came at the end of 1999, when \#30 entered musth, and moved into the northeastern section of the park, which is 
where the largest female groups ranged (Fig. 2b).

Following initial ranging described above, male \#31 settled into a restricted range in the northeast of the park (Fig. 2c). Male \#31 did venture out for 2 weeks from 25 July to 8 August 1998 and again from 4 January to 24 February 1999 (Appendix A). While not in musth, male \#31 spent less time in the centre of the reserve (Figs. 2c, 2e, 2g) than the other males (Figs. 2a, 2i, 2k, 2m, 2o, 2q, 2s).

After an initial foray, male \#32 settled into a restricted home range in the centre of the park (Fig. 2i). Male \#32 range while in musth was more extensive, and included the northeast that he had previously not visited (Fig. 2j). Following his first musth period male \#32 returned to a core range in the centre of the reserve, in a similar area to that before musth (Fig. 2k). During this period his core range was restricted to only $7.1 \mathrm{~km}^{2}$ (50\% kernel). During male \#32's second musth period his range did not shift from the centre of the reserve (Fig. 2l). Male \#32 may have been excluded from the northeast by male \#30 who was also in musth at that time (Appendix A), and spending time in the northeast (Fig. 2b).

After a very extensive ranging, male \#34 settled into a restricted range in the centre of the park (Fig. 2m). Male \#34's range increased during his first musth period to include the wilderness area to the northwest, where the female groups were located at that time (Fig. 2n). After musth, male 34 returned to the centre of the park (Fig. 2o), while during his second musth period, the range shifted to the female herds in the northeast (Fig. 2p).

Male \#35 spent a lot of time associated with male \#34, and also settled in the centre of the reserve during non-musth periods (Fig. 2q, s). While in musth, male \#35's range shifted to the northeast (Fig. 2r, t).

\section{Behaviour during musth periods}

The five males that entered musth (all excluding male \#33) showed different behaviour when in musth relative to their
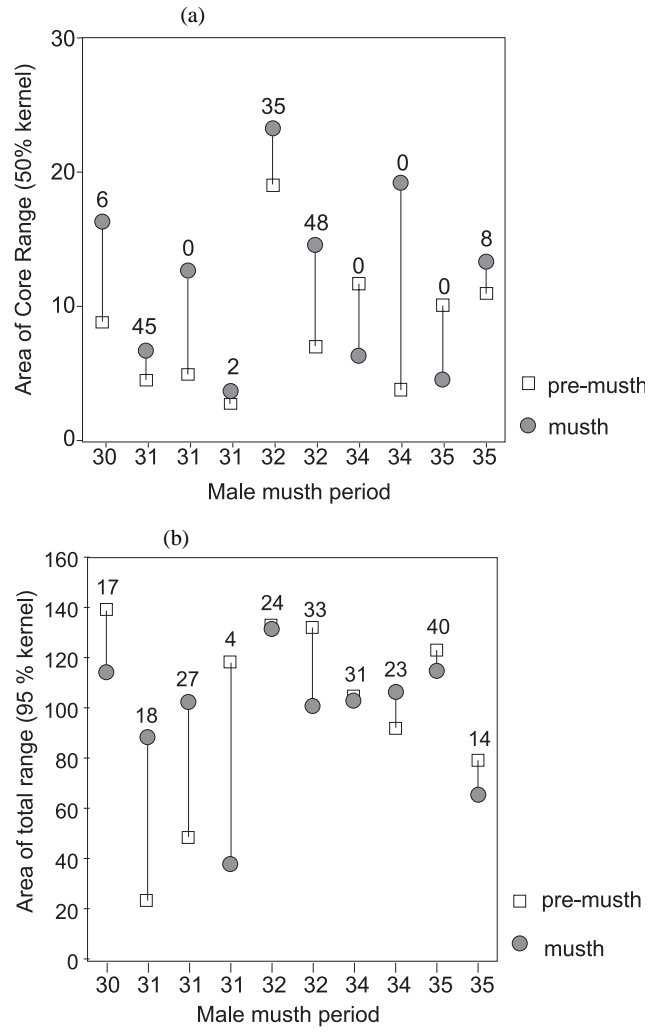

Fig. 3. Contrast of spatial use before and during musth. We present area $\left(\mathrm{km}^{2}\right)$ of (a) core range (50\% Kernel), and (b) overall range (95\% kernel). We also present percent overlap of the range during musth with that before musth as numbers above each data-pair.

non-musth behaviour. The core range (50\% kernel) sizes of males in musth were larger than when they were not in musth (Fig. 3a). This difference was not statistically significant (Wilcoxon paired signed ranks test: $z=$ -1.753: $n=5$ males with values averaged when more than one musth period occurred, $p=0.08$ ). Given the small samples size of this test, this is probably a biologically significant result. There was no significant difference in the area of overall range of males when in musth relative to the period before musth (Fig. 3b: Wilcoxon test: $z=-0.94: n=$ $5, p=0.345)$. 
During musth, the older introduced males shifted their range use, moving into areas that they did not normally frequent. This is indicated by the low overlap in core ranges when in musth relative to out of musth (Fig. 3). The median percent overlap of core range (50\% kernel) was only $4 \%$, while that of overall range was also relatively low at $23 \%$. This range shift was primarily in response to the ranging patterns of the female groups. We illustrate this shift by contrasting the overlap of male ranges with female ranges for the period before musth and after musth (Fig. 4). There was a statistically significant increase in the percentage overlap of core range (50\% kernel) of male range with female range from pre-musth to musth periods (Wilcoxon paired signed ranks test: $z=-2.023, n=5$ males, $p=$ $0.043)$. There was no significant difference in the degree of overlap of overall (95 \% kernel) male range with female range from premusth to musth periods (Wilcoxon paired signed ranks test: $z=-0.135, n=5$ males, $p=0.893)$.

Males walked significantly longer distances when in musth relative to the period before musth (Fig. 5: Wilcoxon paired signed ranks test: $z=-2.023, n=5$ males, $p=0.043$ ). This increased distance is probably a consequence of their association with females that are moving longer distances, or from moving between female groups, than any causal factor among the males themselves.

Male \#33 showed different behaviour because of the close association with the largest breeding herd. Male \#33 was the youngest of the introduced males (Table 1), and had not yet entered musth by February 2001.

\section{Discussion}

This introduction was successful in that it met the objective of reducing the mortality of rhino through suppression of musth in younger males (Slotow et al. 2000). This project was also the first to translocate adult male elephant (over the age of 25 years old),
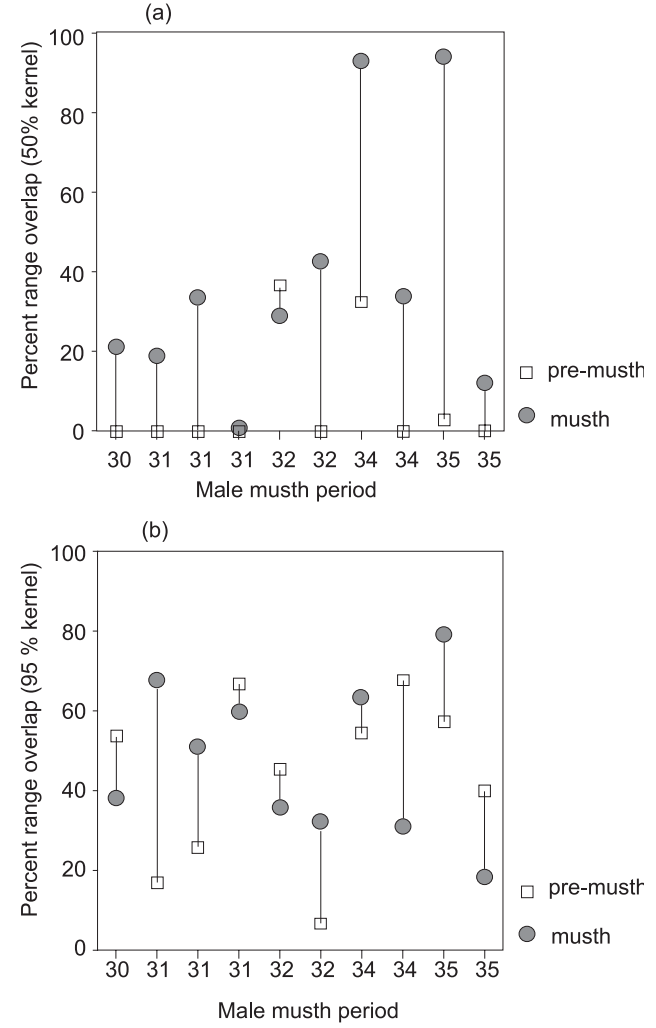

Fig. 4. Association of older introduced males with females before and during musth. We present overlap of ranges of males with those of females over the same period, and present percent overlap of their ranges during musth with those before musth for (a) core range (50\% kernel) and (b) overall range (95\% kernel).

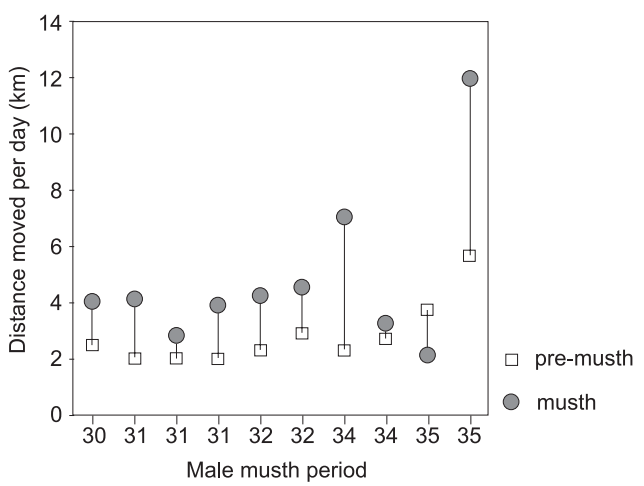

Fig. 5. Contrast of distance moved $(\mathrm{km})$ before and during musth. 
and was successful in that the introduced animals settled well into the park. That there were no breakouts is in contrast to subsequent introductions to other reserves where about half of introductions have resulted in a breakout (Garai \& Carr 2001). The lack of breakouts is not related to the relatively large size of Pilanesberg, since all males approached the boundary fence soon after introduction, and some spent extended periods in the area adjacent to the fence.

The behaviour of the males following introduction is indicative of the well developed social structure, and high levels of intelligence of elephant. All individuals exhibited some exploratory behaviour, and all except male \#31 immediately linked up with at least one other male. In some cases, these were the existing resident elephants. Although the males appeared to settle rapidly into the reserve, their musth patterns may indicate that they were stressed by their translocation. The soonest musth was after six months (male \#31), but male \#33 had not entered musth by the end of 2001 (three years after introduction). Male \#30 took almost 2 years to enter musth (see Slotow et al. 2000 for details of musth periods). Although we do not know their previous musth history, as the oldest elephants in the reserve, they should not have been constrained from entering musth, even if only for short periods, so we believe that the delay in entering musth must have been from an environmental stressor such as translocation to a new environment.

The elephant used a relatively small home range (mean $95 \%$ kernel $=99.7 \mathrm{~km}^{2}$ for non-musth periods). This is especially evident when considering the core range of the animals (mean $50 \%$ kernel $=8.4 \mathrm{~km}^{2}$ for non-musth periods). There was no change in the total range size during musth, but there was a small increase in core range size (to $12.1 \mathrm{~km}^{2}$ ). These range sizes are much smaller than those documented (157-465 $\left.\mathrm{km}^{2}\right)$ for male elephant from the nearest comparable population (reserves adjacent to the Kruger National Park, i.e., their origin population) (De Villiers \& Kok 1997). Hall-Martin (1984) gives values of $436 \mathrm{~km}^{2}$ for female elephants in Kruger National Park). The ranges observed in Pilanesberg are comparable to some other areas, such as Lake Manyara $\left(57 \mathrm{~km}^{2}\right)$ and the Zambezi Valley $\left(156 \mathrm{~km}^{2}\right)$ (Dunham 1986). Addo Elephant National Park (AENP) is a fenced area of $103 \mathrm{~km}^{2}$ and male elephants there had a mean $100 \%$ kernel range of $52.8 \mathrm{~km}^{2}$ (Whitehouse \& Schoeman 2003). At AENP, the core $50 \%$ range of non-musth males was $8.4 \mathrm{~km}^{2}$ (Whitehouse \& Schoeman 2003), which is exactly the same as observed by us in Pilanesberg. This coincidence may indicate a lower-limit requirement by male elephant, which is unlikely to be related to water (widespread in both reserves) or food (Addo has a much higher food quality than Pilanesberg (pers. obs.), and see references in Whitehouse \& Schoeman 2003). Thouless (1996) suggested that range size is correlated with rainfall, with smaller ranges at higher rainfall. The rainfall of Pilanesberg is in fact within the range of the Kruger National Park, and according to this hypothesis we would predict a range several times larger than manifested (bearing in mind that these animals, in fact, originated from Kruger National Park). Note that elephant home ranges are in the $1000 \mathrm{sm}^{2}$ in some populations (Lindeque \& Lindeque 1991; Demeke \& Bekele 2000).

The introduced elephants moved, on average, $2.1 \mathrm{~km}$ between sightings on the same day. In Addo, the most frequently observed daily movement was in all cases $<2.4 \mathrm{~km}$ (Fig. 4 in Whitehouse \& Schoeman 2003). This is less than half the distance noted for elephant in the Sengwa Valley area of Zimbabwe (Guy 1976), and much lower than the $14.1 \mathrm{~km}$ traveled per day by male elephants in the area adjacent to Kruger National Park - calculated by dividing the distance traveled by the number of days between observations, i.e., more comparable to our measurements between days (De Villiers \& Kok 1997). Continuous studies of elephant indicate rates of movement of about $0.5 \mathrm{~km} / \mathrm{h}$ (Wyatt \& Eltringham 1974). The disparity in these figures implies that the animals in Pilanesberg could be backtracking on themselves, rather than moving in straight lines 
over longer distances. This would indeed result in the relatively small ranges of the introduced Pilanesberg animals. Note that water is abundant in Pilanesberg, with the whole of the park being within $2.5 \mathrm{~km}$ of a source of water. The lack of a need for water may result in the shorted distances traveled. The range sizes are in fact within the lower range of those from northern Botswana, specifically those closest to water (Verlinden \& Gavor 1998).

There is a very strong social influence on male behaviour, with the males changing their range and distances moved when they enter musth. Essentially males are joining the female groups, as observed in Addo (Whitehouse \& Schoeman 2003), which results in a shift in spatial use and an increase in distances moved. This result has an important implication. Even in areas as small as Pilanesberg National Park, the male elephant are spending most of their time in 'bull areas', and then move from these to be with the females when in musth. This is an interesting result, because there is a lot of overlap in non-musth male and female ranges. In other words, the areas are not spatially exclusive. However, the areas are temporally exclusive. These results are encouraging because they indicate that even in areas as small as Pilanesberg National Park, there is the potential for a normal elephant social network to be established.

\section{Management implications}

Each of the large males are thus using about $20 \%$ of the reserve for their total range, but only $2 \%$ of the reserve for their core range. This implies that large elephant may well be maintained on very small reserves.

The small ranges used by these males indicate that vegetation use is going to be extremely heterogeneous, particularly as males associate with each other in small groups, and stocking rates should not be calculated on averages across reserves, but rather on spatial usage patterns. This implies a strong need for research on spatial use by elephant on each reserve where they occur in order to sensibly model their potential ecological impact.

'Bull areas' exist even on small reserves, which imply a higher probability of encounters between large males in those areas. Knowledge of bull areas will allow infrastructure planning to enhance tourism sightings (place lodge in bull area), and reduce destruction of materials (place machinery outside bull area). Managers and planners of small reserves must aim to provide the necessary environmental characteristics that encourage the separation of male and female elephant into their natural social system. Further study is necessary to elucidate the features and factors that govern spatial and temporal separation of home ranges of nonmusth male and female elephant.

This study emphasises the importance of detailed study of individually identified large mammals in fundamental understanding of key management issues, and any management plan for elephant should incorporate such study for effective adaptive management to be implemented.

\section{Acknowledgements}

This paper is dedicated to the memory of Andre Klocke, who was killed by an elephant in Botswana in 2000. We thank Andre Klocke and Donald Sutton for collecting most of the data used in this paper. We thank also all the others who contributed observations. This study was funded by Pretoria Portland Cement, Distell (Amarula), Total Petrolium, the South African Broadcasting Corporation (programme 50/50), the National Research Foundation, the University of Natal, and North West Parks and Tourism Board.

\section{References}

BRown, G. 1993. The viewing value of elephants. Pp. 146-156. In: Barber, E.B. (Ed.) Economics and Ecology: New frontiers and sustainable development. London: Chapman \& Hall.

Caughley, G. 1976. The elephant problem-an alternative hypothesis. East African Wildlife Journal 14: 265-283.

Cumming, D.H.M., M.B. Fenton, I.L. Rautenbach, R.D. TAYlor, G.S. Cumming, M.S. Cumming, 
J.M. Dunlop, A.G. Ford, M.D. HovorKa, D.S. Johnston, M. Kalcounis, Z. Mahlangu \& C.V.R. PORTFOrs. 1997. Elephants, woodlands and biodiversity in southern Africa. South African Journal of Science 93: 231-236.

Demeke, Y. \& A. BeKele. 2000. Study on the elephants of Mago National Park, Ethiopia. Pachyderm 28: 32-43.

De Villiers, P.A. \& O.B. KoK. 1997. Home ranges, association and related aspects of elephants in the eastern Transvaal lowveld. African Journal of Ecology 35: 224-236.

Dublin, H.T., A.R.E. Sinclair \& J.McGlade. 1990. Elephants and fire as causes of multiple stable states in the Serengeti-Mara woodlands. Journal of Animal Ecology 59: 1147-1164.

DunHAM, K.M. 1986. Movements of elephant cows in the unflooded Middle Zambezi Valley, Zimbabwe. African Journal of Ecology 24: 287-291.

GARAI, M.E. \& R.D. CARR. 2001. Unsuccessful introductions of adult elephant bulls to confined areas in South Africa. Pachyderm 31: 52-57.

GuY, P.R. 1976. Diurnal activity patterns of elephant in the Sengwa Area, Rhodesia. East African Wildlife Journal 14: 285-295.

Hall-Martin, A.J. 1984. Conservation and management of elephants in the Kruger National Park, South Africa. Pp. 104-118. In: Cumming, D.H.M \& P. JACKSON (eds.). The status and conservation of Africa's elephants. Proceedings of the joint meeting of IUCN/SSC African Elephant and African Rhino Specialist Groups, 30 July - 7 August, 1981, Hwange Safari Lodge, Zimbabwe. Gland: IUCN.

Hooge, P.N. \& B. Eichenlaub. 1997. Animal movement extension to Arcview, Version 1.1. Anchorage, Alaska: Alaska Biological Science Center, U.S. Geological Survey.

Lindeque, M. \& P.M. Lindeque. 1991. Satellite tracking of elephants in northern Namibia. African Journal of Ecology 29: 196-206.
PooLE, J.H. 1987. Rutting behaviour in African elephants: the phenomenon of musth. Behaviour 102: 283-316.

Slotow, R., D. Balfour \& O. Howison. 2001. Killing of black and white rhinoceroses by African elephants in Hluhluwe-Umfolozi Park, South Africa. Pachyderm 31: 14-20.

Slotow, R., G. van Dyk, J. Poole, B. Page \& A. KLOCKE. 2000. Older bull elephants control young males. Nature 408: 425-426.

SLOTOW, R. \& G. vAN DYK. 2001. Role of delinquent young 'orphan' male elephants in high mortality of white rhinoceros in Pilanesberg National Park, South Africa. Koedoe 44: 85-94.

TAYLOR, R.D. 1993. Elephant management in Nyaminyami District, Zimbabwe: Turning a liability into an asset. Pachyderm 17: 19-29.

Thouless, C.R. 1996. Home ranges and social organization of female elephants in northern Kenya. African Journal of Ecology 34: 284-297.

VAN DE ViJVer, C.A.D.M., C.A. Foley \& H. OLfF.1999. Changes in the woody component of an East African savanna during 25 years. Journal of Tropical Ecology 15: 545-564.

Verlinden, A. \& I.K.N. GaVor. 1998. Satellite tracking of elephants in northern Botswana. African Journal of Ecology 36: 105-116.

Whitehouse, A. M. \& D.S. Schoeman. 2003. Ranging behaviour of elephants within a small fenced area in Addo Elephant National Park, South Africa. African Zoology 38: 95-108.

WorTON, B.J. 1989. Kernel methods for estimating the utilization distribution in home-range studies. Ecology 70: 164-168.

WyATT, J.R. \& S.K. Eltringham. 1974. The daily activity of the elephant in Rwenzori National Park, Uganda. East African Wildlife Journal 12: 273-289. 


\section{Appendix A}

Breakdown of distances moved $(\mathrm{km})$ by individuals during different periods depending on each individual's state. Sample sizes are number of observations. Same day refers to distances between two points on the same day. Subsequent day refers to distances between two points on subsequent days. Distances are straight line distances averaged for same day or subsequent day within each period. These averages were then averaged for each state for analysis and interpretation. Ranges are only illustrated for periods that were

\begin{tabular}{|c|c|c|c|c|c|c|c|c|c|c|c|c|}
\hline \multicolumn{13}{|c|}{$\begin{array}{r}\text { analysed } \\
\end{array}$} \\
\hline \multirow[b]{2}{*}{ ID } & \multirow[b]{2}{*}{$\begin{array}{l}\text { Start } \\
\text { date }\end{array}$} & \multirow[b]{2}{*}{$\begin{array}{l}\text { End } \\
\text { date }\end{array}$} & \multirow[b]{2}{*}{ State } & \multirow[b]{2}{*}{ Days } & \multirow[b]{2}{*}{$\begin{array}{l}\text { Total } \\
\mathrm{N}\end{array}$} & \multicolumn{2}{|c|}{ Same day } & \multicolumn{2}{|c|}{ Next day } & \multirow{2}{*}{$\begin{array}{c}\text { Core } \\
\text { Range } \\
50 \% \text { kernel } \\
\left(\mathrm{km}^{2}\right)\end{array}$} & \multirow{2}{*}{$\begin{array}{c}\text { Total } \\
\text { Range } \\
\text { 95\% kernel } \\
\left(\mathrm{km}^{2}\right)\end{array}$} & \multirow[b]{2}{*}{ Fig } \\
\hline & & & & & & $\overline{\mathrm{N}}$ & $\begin{array}{l}\text { Mean } \\
\text { Distance } \\
(\mathrm{km})\end{array}$ & $\mathrm{N}$ & $\begin{array}{c}\text { Mean } \\
\text { Distance } \\
(\mathrm{km})\end{array}$ & & & \\
\hline 30 & 7/2/98 & 7/3/98 & initial & 28 & 24 & 4 & 3.0 & 16 & 5.4 & & & 1a \\
\hline 30 & 8/3/98 & 24/3/98 & settled & 16 & 17 & 4 & 0.7 & 10 & 2.4 & & & 1a \\
\hline 30 & 26/3/98 & 29/4/98 & move & 34 & 48 & 16 & 2.1 & 28 & 2.6 & & & $1 \mathrm{~b}$ \\
\hline 30 & $1 / 5 / 98$ & 31/5/98 & settled & 30 & 31 & 9 & 1.0 & 17 & 2.0 & & & $1 \mathrm{~b}$ \\
\hline 30 & $1 / 6 / 98$ & 30/6/98 & settled & 29 & 23 & 3 & 1.9 & 15 & 2.5 & & & 1c \\
\hline 30 & $1 / 7 / 98$ & 13/7/98 & move & 12 & 19 & 6 & 1.8 & 13 & 2.5 & & & 1c \\
\hline 30 & $14 / 7 / 98$ & 24/7/98 & settled & 10 & 20 & 9 & 0.7 & 11 & 1.8 & & & \\
\hline 30 & 25/7/98 & 10/8/98 & move & 16 & 44 & 3 & 0.8 & 22 & 3.0 & & & 1c \\
\hline 30 & $12 / 10 / 98$ & 29/12/98 & range & 78 & 47 & 9 & 1.5 & 23 & 2.4 & & & \\
\hline 30 & 4/1/99 & 17/12/99 & range & 347 & 71 & 4 & 3.3 & 21 & 2.6 & 8.9 & 139.4 & $2 a$ \\
\hline 30 & 24/12/99 & 28/2/00 & musth & 66 & 17 & 1 & 4.5 & 8 & 4.1 & 16.3 & 114.8 & $2 b$ \\
\hline 31 & 7/2/98 & 17/2/98 & initial & 10 & 8 & 0 & 0.0 & 5 & 3.8 & & & $1 \mathrm{~d}$ \\
\hline 31 & 18/2/98 & 3/3/98 & settled & 13 & 8 & 1 & 1.4 & 3 & 4.1 & & & $1 \mathrm{~d}$ \\
\hline 31 & 4/3/98 & 13/3/98 & move & 9 & 7 & 1 & 0.5 & 5 & 1.7 & & & $1 \mathrm{~d}$ \\
\hline 31 & 14/3/98 & $1 / 4 / 98$ & settled & 18 & 7 & 0 & 0.0 & 3 & 0.6 & & & $1 \mathrm{e}$ \\
\hline 31 & 2/4/98 & 13/4/98 & move & 11 & 9 & 0 & 0.0 & 6 & 2.6 & & & $1 \mathrm{e}$ \\
\hline 31 & $14 / 5 / 98$ & 25/7/98 & settled & 72 & 42 & 7 & 1.8 & 20 & 2.7 & & & \\
\hline 31 & 27/7/98 & 7/8/98 & move & 11 & 8 & 2 & 0.9 & 3 & 4.3 & & & \\
\hline 31 & 9/8/98 & 2/9/98 & settled & 24 & 12 & 2 & 2.3 & 4 & 2.1 & 4.6 & 24 & $2 \mathrm{c}$ \\
\hline 31 & 11/9/98 & 2/11/98 & musth & 52 & 47 & 13 & 2.0 & 23 & 4.2 & 6.8 & 89.2 & $2 d$ \\
\hline 31 & 3/11/98 & 24/11/98 & range & 21 & 18 & 3 & 1.5 & 10 & 2.1 & 5 & 49.4 & $2 \mathrm{e}$ \\
\hline 31 & 25/11/98 & 4/1/99 & musth & 40 & 29 & 9 & 2.8 & 12 & 2.9 & 12.7 & 102.9 & $2 \mathrm{f}$ \\
\hline 31 & 6/1/99 & 23/2/99 & range & 48 & 16 & 2 & 0.7 & 4 & 2.1 & & & \\
\hline 31 & 2/3/99 & 6/10/99 & range & 218 & 44 & 4 & 3.7 & 13 & 4.0 & 2.8 & 118.7 & $2 \mathrm{~g}$ \\
\hline 31 & 18/10/99 & 23/11/99 & musth & 36 & 2 & 0 & 0.0 & 0 & & 3.8 & 38.9 & $2 \mathrm{~h}$ \\
\hline 31 & 11/11/99 & 27/12/99 & range & 46 & 4 & 1 & 0.4 & 0 & & & & \\
\hline 31 & 31/12/99 & $5 / 1 / 00$ & musth & 5 & 5 & 2 & 2.8 & 2 & 6.7 & & & \\
\hline 31 & $6 / 1 / 00$ & $21 / 2 / 00$ & range & 46 & 7 & 0 & 0.0 & 3 & 6.8 & & & \\
\hline 32 & 22/3/98 & 15/4/98 & initial & 24 & 30 & 8 & 2.1 & 19 & 3.4 & & & $1 \mathrm{f}$ \\
\hline 32 & $16 / 4 / 98$ & 25/11/98 & range & 223 & 188 & 46 & 1.8 & 101 & 2.4 & 19.1 & 133.1 & $2 \mathrm{i}$ \\
\hline 32 & 28/11/98 & 10/1/99 & musth & 43 & 29 & 6 & 1.9 & 15 & 4.3 & 23.3 & 132.1 & $2 \mathrm{j}$ \\
\hline 32 & 11/1/99 & 13/12/99 & range & 336 & 70 & 7 & 1.7 & 15 & 3.0 & 7.1 & 132.5 & $2 \mathrm{k}$ \\
\hline 32 & 16/12/99 & $16 / 2 / 00$ & musth & 62 & 16 & 2 & 2.3 & 5 & 4.6 & 14.6 & 101.1 & $2 l$ \\
\hline 33 & 23/3/98 & 2/4/98 & initial & 10 & 7 & 1 & 0.7 & 3 & 5.5 & & & $1 \mathrm{~g}$ \\
\hline 33 & 3/4/98 & 25/6/98 & with & 83 & 61 & 9 & 2.9 & 31 & 3.8 & & & \\
\hline 33 & 27/6/98 & 18/9/98 & away & 83 & 48 & 8 & 1.3 & 20 & 3.4 & & & \\
\hline 33 & 19/9/98 & 19/1/99 & with & 122 & 93 & 28 & 2.0 & 43 & 3.6 & & & \\
\hline 33 & 23/1/99 & 19/3/99 & away & 55 & 21 & 2 & 1.8 & 7 & 5.0 & & & \\
\hline 33 & 21/3/99 & 22/5/99 & with & 62 & 24 & 4 & 2.2 & 8 & 3.4 & & & \\
\hline 33 & 3/6/99 & 21/11/99 & away & 171 & 15 & 0 & & 2 & 5.3 & & & \\
\hline 33 & $7 / 1 / 00$ & $28 / 2 / 00$ & with & 52 & 13 & 3 & 1.1 & 2 & 6.2 & & & \\
\hline
\end{tabular}


Appendix A (continued)

\begin{tabular}{|c|c|c|c|c|c|c|c|c|c|c|c|c|}
\hline \multirow[b]{2}{*}{ ID } & \multirow[b]{2}{*}{$\begin{array}{l}\text { Start } \\
\text { date }\end{array}$} & \multirow[b]{2}{*}{$\begin{array}{l}\text { End } \\
\text { date }\end{array}$} & \multirow[b]{2}{*}{ State } & \multirow[b]{2}{*}{ Days } & \multirow[b]{2}{*}{$\begin{array}{c}\text { Total } \\
\text { N }\end{array}$} & \multicolumn{2}{|c|}{ Same day } & \multicolumn{2}{|c|}{ Next day } & \multirow{2}{*}{$\begin{array}{c}\text { Core } \\
\text { Range } \\
50 \% \text { kernel } \\
\left(\mathrm{km}^{2}\right)\end{array}$} & \multirow{2}{*}{$\begin{array}{c}\text { Total } \\
\text { Range } \\
95 \% \text { kernel } \\
\left(\mathrm{km}^{2}\right)\end{array}$} & \multirow[b]{2}{*}{ Fig } \\
\hline & & & & & & $\overline{\mathrm{N}}$ & $\begin{array}{l}\text { Mean } \\
\text { Distance } \\
(\mathrm{km})\end{array}$ & $\overline{\mathrm{N}}$ & $\begin{array}{l}\text { Mean } \\
\text { Distance } \\
(\mathrm{km})\end{array}$ & & & \\
\hline 34 & 13/3/98 & 24/4/98 & initial & 42 & 62 & 22 & 2.1 & 37 & 3.2 & & & $1 \mathrm{~h}$ \\
\hline 34 & 25/4/98 & 5/12/98 & range & 224 & 188 & 38 & 1.7 & 110 & 2.4 & 11.8 & 105.2 & $2 \mathrm{~m}$ \\
\hline 34 & 7/12/98 & 28/1/99 & musth & 52 & 20 & 5 & 3.2 & 4 & 7.1 & 6.4 & 103.3 & $2 \mathrm{n}$ \\
\hline 34 & 10/2/99 & 11/6/99 & range & 121 & 68 & 11 & 1.7 & 32 & 4.0 & & & \\
\hline 34 & 23/6/99 & 13/12/99 & range & 173 & 28 & 1 & 4.5 & 6 & 4.8 & 3.8 & 92.4 & 20 \\
\hline 34 & 16/12/99 & $7 / 2 / 00$ & musth & 53 & 22 & 4 & 2.0 & 11 & 3.3 & 19.2 & 106.6 & $2 p$ \\
\hline 35 & 13/3/98 & 24/4/98 & initial & 42 & 58 & 21 & 2.0 & 33 & 3.7 & & & \\
\hline 35 & 26/4/98 & 30/5/98 & range & 34 & 39 & 14 & 1.7 & 19 & 2.3 & & & \\
\hline 35 & 31/5/98 & 15/7/98 & range & 45 & 25 & 1 & 0.8 & 15 & 2.0 & & & \\
\hline 35 & 16/7/98 & 13/11/98 & range & 120 & 85 & 12 & 1.0 & 50 & 2.6 & & & \\
\hline 35 & 17/11/98 & $1 / 4 / 99$ & range & 135 & 54 & 9 & 1.7 & 17 & 3.8 & 10.1 & 122.9 & $2 q$ \\
\hline 35 & 10/4/99 & 20/8/99 & musth & 132 & 64 & 14 & 1.0 & 31 & 2.2 & 4.6 & 114.8 & $2 \mathrm{r}$ \\
\hline 35 & 21/8/99 & 19/12/99 & range & 120 & 19 & 1 & 10.4 & 4 & 5.7 & 11 & 79.5 & $2 \mathrm{~s}$ \\
\hline 35 & 10/1/00 & $7 / 2 / 00$ & musth & 28 & 7 & 0 & & 1 & 12.0 & 13.3 & 65.7 & $2 \mathrm{t}$ \\
\hline
\end{tabular}

Status: Initial = initial period after introduction, and before the individual settled in an area. Settled and move are used for individuals 30 and 31, and indicate periods of settlement in an area followed by periods of exploration (see text). Range refers to the period when not in musth and after the initial settleing period. Musth refers to the period in musth. 